\title{
Badania spawalności stali S460N w środowisku wodnym z wykorzystaniem próby Tekken
}

\author{
Weldability testing of S460N steel in water environment \\ by using Tekken test
}

\section{Streszczenie}

Spawanie w środowisku wodnym niesie ze sobą wiele problemów, wśród których najważniejszym jest skłonność stali do powstawania pęknięć zimnych. O ile w przypadku spawania na powietrzu istnieje wiele metod zapobiegania tym pęknięciom, o tyle pod wodą zastosowanie tych metod jest ograniczone. Z tego powodu konieczne jest określenie skłonności danego materiału do pękania zimnego.

W pracy oceniono spawalność drobnoziarnistej stali o podwyższonej wytrzymałości S460N podczas spawania mokrego elektrodami otulonymi. Na podstawie wyników próby spawalności Tekken stwierdzono, że złącza wykonane z badanego materiału charakteryzują się wysoką skłonnością do powstania pęknięć zimnych i należy opracować metody pozwalające zniwelować ten problem.

Słowa kluczowe: spawanie podwodne; elektrody otulone; pękanie zimne; stal o podwyższonej wytrzymałości; spawalność

\begin{abstract}
Welding in a water environment carries out a lot of problems, among which the most important could be the susceptibility of steel to cold cracking. There are many methods to prevent these cracks during welding in the air, which couldn't be use in wet welding conditions. For the reason, it is necessary to determine the susceptibility of steel to cold cracking.

The paper presents experimental evaluation of the weldability of fine-grained high strength low alloy S460N steel wet welded by coated electrodes. From the results of Tekken tests it was found out that the investigated steel is characterized by the high susceptibility to cold cracking. It is necessary to look for a method that allows to overcome this problem.
\end{abstract}

Keywords: underwater welding; covered electrodes; cold cracking; high strength low alloy steel; weldability

\section{Wstęp}

Obecnie stosowanych jest wiele procesów spawania pod wodą. Mogą one być sklasyfikowane w zależności od środowiska, w jakim odbywają się prace na trzy podstawowe techniki $[1 \div 3]$ :

- spawanie suche, podczas którego obszar powstającego złącza oraz nurek-spawacz znajdują się w specjalnej komorze i są odizolowani od wody. Wyróżnia się dwie odmiany, spawanie izobaryczne oraz spawanie hiperbaryczne;

- spawanie mokre, podczas którego spawany materiał i nurek-spawacz znajdują się w bezpośrednim kontakcie z wodą;

- spawanie metodą lokalnej komory suchej, podczas którego wykorzystuje się komory o małej objętości, mające na celu częściowe odizolowanie powstającego złącza od środowiska, przy czym nurek-spawacz pozostaje w kontakcie $z$ wodą.

Najczęściej stosowaną ze spawalniczych prac podwodnych jest spawanie mokre z wykorzystaniem elektrod otulonych.
Metoda ta charakteryzuje się bardzo niskimi kosztami, gdyż nie wymaga drogiego, specjalistycznego sprzętu ani żadnych dodatkowych urządzeń. Spawacz ma również stosun-

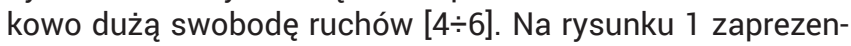
towano schemat spawania mokrego MMA.

Spawanie mokre elektrodami otulonymi przysparza wielu problemów związanych z jakością otrzymywanych złączy $[7,8]$. Środowisko spawania powoduje pogorszenie jakości złączy, które objawia się poprzez: porowatość spoin, zmiany składu chemicznego, czy skłonność do tworzenia pęknięć $[9,10]$. Przyczynami powodującymi te niekorzystne zjawiska są $[11 \div 15]$ :

- obecność wodoru w stopiwie, który pochodzi głównie z pary wodnej otaczającej jarzący się łuk;

- głębokość spawania, z której wynika duża wartość ciśnienia hydrostatycznego, co negatywnie wpływa na stabilność łuku spawalniczego oraz metalurgię jeziorka spawalniczego;

Dr inż. Jacek Tomków, dr inż. Grzegorz Rogalski, dr hab. inż. Dariusz Fydrych, dr hab. inż. Jerzy Łabanowski - Politechnika Gdańska.

Autor korespondencyjny/Corresponding author: jacek.tomkow@pg.edu.pl 


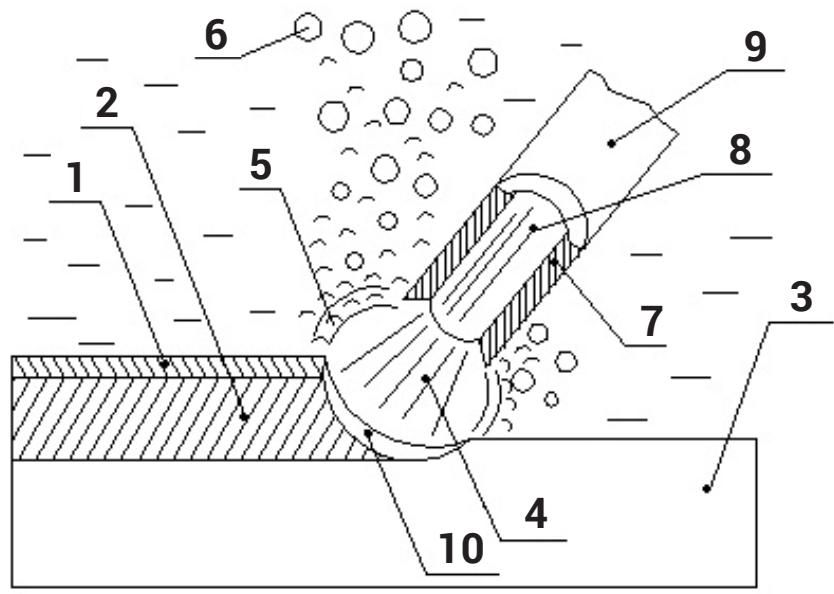

Rys. 1. Schemat spawania pod wodą elektrodą otuloną (metoda mokra): 1 - warstwa żużla, 2 - spoina, 3 - materiał rodzimy, 4 - łuk elektryczny, 5 - para wodna wokół łuku, 6 - pęcherze gazowe, 7 - otulina elektrody, 8 - rdzeń elektrody, 9 - elektroda, 10 - ciekłe jeziorko

Fig. 1. Schematic diagram of underwater wet welding by coated electrodes: 1 - slag, 2 - weld, 3 - base material, 4 - electric arc, 5 - water vapor, 6 - gas bubbles, 7 - flux coating, 8 - core wire, 9 - consumable electrode, 10 - weld pool

- duża szybkość stygnięcia złącza w wyniku intensywnej wymiany ciepła pomiędzy obszarem złącza a otaczającym je środowiskiem wodnym;

- pogorszona widoczność utrudniająca nurkowi-spawaczowi prowadzenie procesu w stabilny sposób, co jest spowodowane gazami spawalniczymi, które uwalniają się podczas spawania, a w wodzie przybierają postać pęcherzy.

Podczas wykonywania złączy w warunkach spawania podwodnego największym problemem, który w głównej mierze decyduje o spawalności, są pęknięcia zimne [16,17].

Wywołane są one równoczesnym oddziaływaniem następujących czynników $[1,4,6,14,18,19]$ :

- kruchej mikrostruktury w SWC;

- wysokich naprężeń w obszarze o niekorzystnej mikrostrukturze;

- obecności wodoru dyfundującego.

Zapobieganie tworzeniu się pęknięć zimnych w przypadku spawania mokrego jest ograniczone w stosunku do wykonywania złączy na powietrzu. Nie ma praktycznej możliwości ograniczenia zawartości wodoru dyfundującego do poziomu procesów niskowodorowych. Suszenie elektrod bądź ich pokrywanie powłokami wodoodpornymi okazuje się metodą nieskuteczną. Środowisko wodne niemal eliminuje możliwość zastosowania metod podgrzewania łączonych materiałów oraz ich późniejszej obróbki cieplnej, wykonywanej w tradycyjny sposób. Najnowsze badania pokazują jednak, że możliwe jest zastosowanie podgrzewania indukcyjnego [20]. Praktyczne zastosowanie znajduje [1,2,11,19]:

- zwiększenie energii liniowej spawania;

- stosowanie elektrod austenitycznych, których stopiwo jest bardziej plastyczne;
- wprowadzenie do otuliny elektrody topnika fluorku wapnia, który w temperaturze spawania wiąże wodór w trwały związek, zmniejszając jego wpływ na powstawanie pęknięć.

Do badań wykorzystano drobnoziarnistą, normalizowaną stal o podwyższonej wytrzymałości S460N. Charakteryzuje się ona granicą plastyczności $R_{e}=511 \mathrm{MPa}$, co zawdzięcza w dużym stopniu większej zawartości pierwiastków stopowych $\mathrm{C}, \mathrm{Mn}, \mathrm{V}$, które powodują bardziej intensywne procesy umocnienia roztworowego i wydzieleniowego mikrostruktury. W konsekwencji równoważnik węgla stali S460N osiągnął wartość $0,46 \%$. Stal wykorzystywana jest na konstrukcje oceano- i hydrotechniczne jak kadłuby statków, czy elementy platform wiertniczych.

\section{Badania własne}

Celem badań była ocena spawalności drobnoziarnistej stali $\mathrm{S} 460 \mathrm{~N}$ o grubości $12 \mathrm{~mm}$ podczas spawania mokrego elektrodami otulonymi. Plan badań zakładał wykonanie złączy prób Tekken zgodnie z wytycznymi normy PN-EN ISO 17642-2:2005. Przygotowano dwanaście próbek, spośród których 10 spawano pod wodą, a dwie na powietrzu. W tablicy I zaprezentowano skład chemiczny stali wg analizy kontrolnej wykonanej metodą spektrometrii emisyjnej ze wzbudzeniem iskrowym. W tablicy II zaprezentowano własności mechaniczne badanej stali.

Eksperyment przeprowadzano w środowisku wody wodociągowej o temperaturze ok. $20^{\circ} \mathrm{C}$ na głębokości $150 \mathrm{~mm}$ na stanowisku do spawania na małych głębokościach, w jakie wyposażone jest laboratorium Zespołu Inżynierii Spajania Politechniki Gdańskiej. Schemat stanowiska zaprezentowano na rysunku 2.

Do wykonania złączy testowych wykorzystano elektrody ogólnego przeznaczenia Omnia (E 380 R 11) o średnicy $4 \mathrm{~mm}$. Wybór tego rodzaju elektrod zdeterminowany był faktem, że zapewniają one dobre własności plastyczne stopiwa,

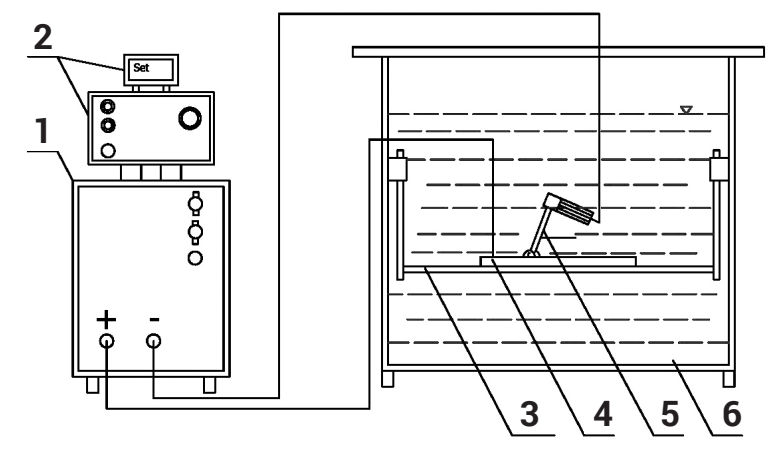

Rys. 2. Schemat stanowiska do spawania na małych głębokościach: 1 - spawalnicze źródło prądu, 2 - panel sterowania, 3 - stół, 4 - spawany element, 5 - elektroda, 6 - zbiornik

Fig. 2. The schema of the stand for the underwater welding at shallow depths: 1 - welding power source, 2 - control panel wire feeder, 3 - table, 4 - plate, 5 - electrode, 6 - tank

Tablica I. Skład chemiczny stali S460N

Table I. Chemical composition of S460N steel (wt. \%)

\begin{tabular}{|c|c|c|c|c|c|c|c|c|c|c|c|}
\hline \multicolumn{12}{|c|}{ Zawartość pierwiastka, \% } \\
\hline & C & Si & Mn & $\mathbf{P}$ & $\mathrm{Cr}$ & Mo & $\mathrm{Ni}$ & Al & $\mathrm{Cu}$ & v & $\mathrm{Ce}_{\text {мIs }}$ \\
\hline wg analizy kontrolnej & 0,16 & 0,53 & 1,51 & 0,02 & 0,07 & 0,03 & 0,05 & 0,033 & 0,13 & 0,097 & 0,464 \\
\hline
\end{tabular}


Tablica II. Własności mechaniczne stali S460N Table II. Mechanical properties of S460N steel

\begin{tabular}{|c|c|c|}
\hline $\begin{array}{c}\text { Granica } \\
\text { plastyczności } \\
\mathbf{R}_{\mathrm{e}} \text { [MPa] }\end{array}$ & $\begin{array}{c}\text { Wytrzymałość } \\
\text { na rozciąganie } \\
\mathbf{R}_{\mathrm{m}}[\mathrm{MPa}]\end{array}$ & $\begin{array}{c}\text { Wydłużenie } \\
\mathbf{A}_{\mathbf{5}}[\%]\end{array}$ \\
\hline 511 & 626 & 27,3 \\
\hline
\end{tabular}

Tablica III. Skład chemiczny oraz własności mechaniczne rutylowych elektrod Omnia [24]

Table III. Chamical composioton (wt. \%) and mechanical properties of Omnia rutile electrodes

\begin{tabular}{|c|c|c|c|c|c|}
\hline \multicolumn{2}{|c|}{ Skład chemiczny (\% wag) } & \multicolumn{3}{c|}{ Własności mechaniczne } \\
\hline C & Mn & Si & $\mathbf{R}_{\mathrm{e}}[\mathrm{MPa}]$ & $\mathbf{R}_{\mathrm{m}}[\mathrm{MPa}]$ & $\mathbf{A}_{5}[\%]$ \\
\hline 0,07 & 0,55 & 0,44 & 503 & 538 & 26 \\
\hline
\end{tabular}

co miało na celu zmniejszyć skłonność złączy do pękania. Spawano prądem stałym z biegunowością ujemną (DC-) zgodnie z zaleceniami producenta. Skład chemiczny oraz własności mechaniczne zastosowanych elektrod przedstawiono w tablicy III.

Próbki oznaczono literami (W - spawana pod wodą, P spawana na powietrzu) oraz kolejnymi kolejnymi cyframi arabskimi. Parametry procesu zaprezentowano w tablicy IV.

\section{Badania nieniszczące}

Próbki poddano badaniom nieniszczącym po upływie 72 godzin od zakończenia spawania. Przeprowadzono je zgodnie z zaleceniami norm PN-EN ISO 17637:2017-02 (VT) i PN-EN ISO 3452-1:2013-08 (PT). W badaniach wizualnych za spoiny akceptowalne uznawano spoiny o poziomie jakości B wg PN-EN ISO 17637:2017-02. W badaniach penetracyjnych jako akceptowalne uznano spoiny o poziomie akceptacji 2x wg PN-EN ISO 3452-1:2013-08. Na rysunku 3 zaprezentowano przykładowe wyniki badań nieniszczących.

\section{Badania metalograficzne makroskopowe}

Badania metalograficzne zostały przeprowadzone zgodnie z wytycznymi normy PN-EN ISO 17639:2013-12. Przekroje próbek spawanych pod wodą wykazywały obecność pęknięć we wszystkich złączach. Obserwowano głównie
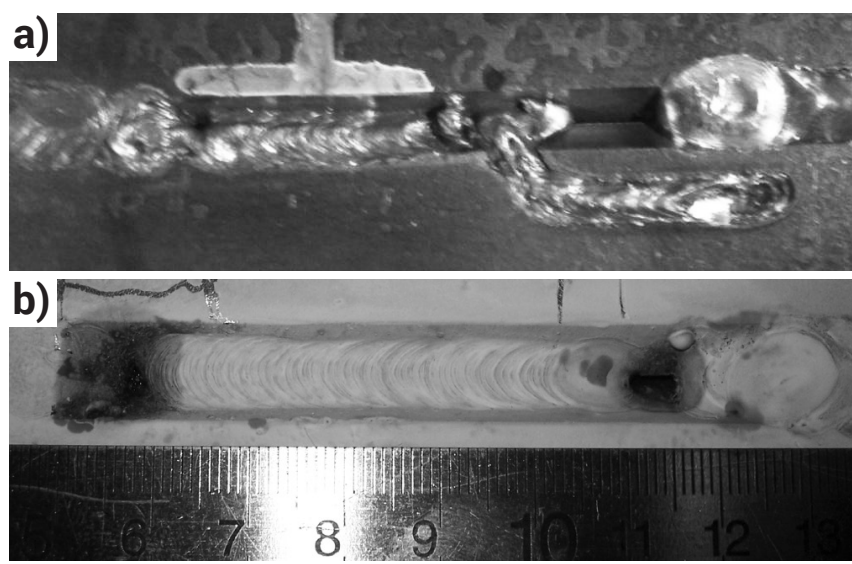

Rys. 3. Przykładowe wyniki badań nieniszczących: a) VT, próbka wykonana pod wodą W6, ścieg poza rowkiem, złącze nieakceptowalne, b) PT, próbka wykonana na powietrzu P11, brak niezgodności, złącze akceptowalne try spawania próbek CTS

Fig. 3. Exemplary results of non-destructive testing: a) VT, specimen W6 welded in the water, wrong shape, weld not approved, b) PT, specimen P11 welded in the air, no imperfections, weld approved
Tablica IV. Parametry spawania próbek CTS

Table IV. Welding conditions of CTS tests

\begin{tabular}{|c|c|c|c|c|c|}
\hline Nr próbki & I, [A] & $\mathbf{U}[\mathrm{V}]$ & $\mathbf{t}[\mathbf{s}]$ & Vsp [mm/s] & ql [kJ/mm] \\
\hline \multicolumn{6}{|c|}{ Próbki wykonane pod wodą } \\
\hline W1 & 188 & 22,3 & 20,1 & 3,98 & 1,05 \\
\hline W2 & 184 & 24,5 & 16,3 & 4,91 & 0,92 \\
\hline W3 & 188 & 23,0 & 22,9 & 3,49 & 1,24 \\
\hline W4 & 196 & 25,8 & 26,2 & 3,05 & 1,66 \\
\hline W5 & 200 & 23,0 & 18,1 & 4,42 & 1,04 \\
\hline W6 & 196 & 25,3 & 25,0 & 3,20 & 1,55 \\
\hline W7 & 204 & 26,3 & 17,0 & 4,71 & 1,14 \\
\hline W8 & 204 & 26,8 & 18,1 & 4,42 & 1,25 \\
\hline W9 & 192 & 32,5 & 14,0 & 5,71 & 1,09 \\
\hline W10 & 204 & 26,8 & 16,3 & 4,91 & 1,11 \\
\hline \multicolumn{7}{|c|}{ Próbki wykonane na powietrzu } & \\
\hline P11 & 152 & 23,2 & 20,0 & 4,00 & 0,88 \\
\hline P12 & 146 & 27,0 & 18,2 & 4,40 & 0,90 \\
\hline
\end{tabular}

pęknięcia przebiegające wzdłuż linii wtopienia, niekiedy przechodzące do spoiny. Ujawniono również pęknięcia w SWC. Dla wszystkich próbek, które wykonano na powietrzu zanotowano obecność pęknięć. Przykładowe wyniki badań makroskopowych zaprezentowano na rysunku 4.

a)

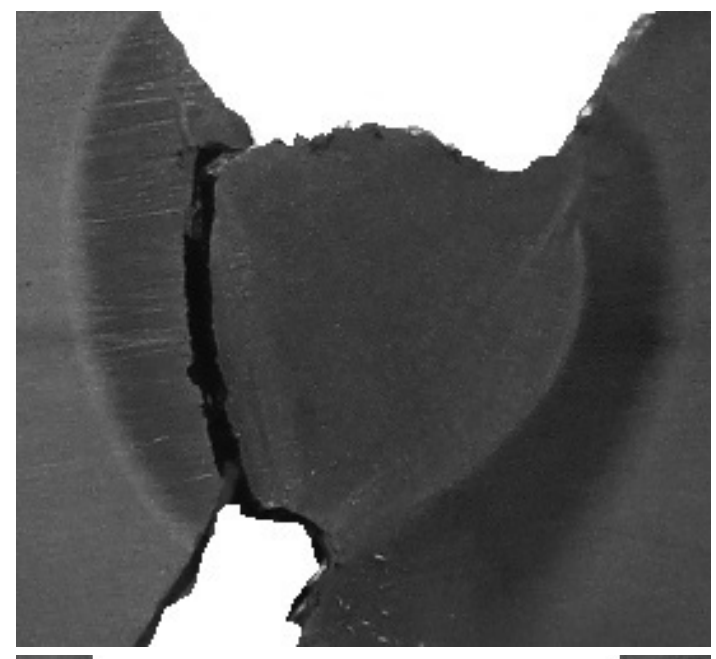

b)

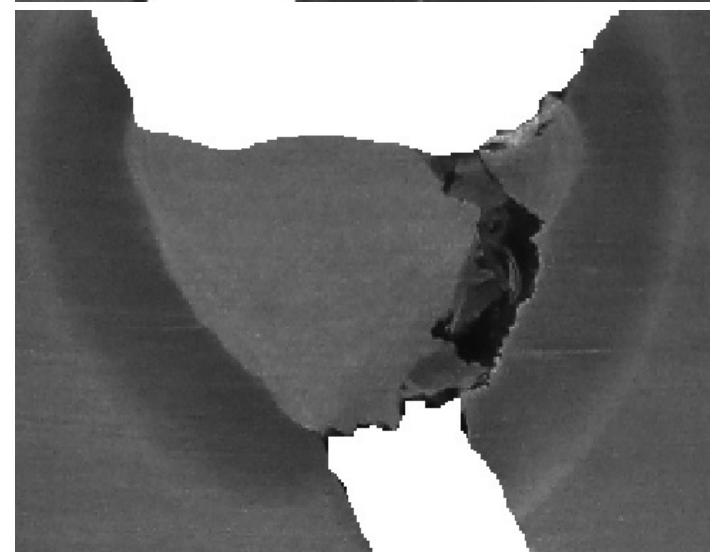

Rys. 4. Przykładowe wyniki badań makroskopowych: a) próbka W9 wykonana pod wodą, pęknięcie przebiegające po linii wtopienia, przechodzące w spoinę, b) próbka P11 wykonana na powietrzu, pęknięcie przebiegające po linii wtopienia, przechodzące w spoinę Fig. 4. Exemplary results of macroscopic testing: a) specimen W9 welded in the water, crack goes from fusion line to weld, b) specimen P11 welded in the air, crack goes from fusion line to weld 


\section{Pomiary twardości}

Pomiary twardości metodą Vickersa wykonano zgodnie z wymaganiami przedmiotowej normy PN-EN ISO 90151:2011, wg schematu zaprezentowanego na rysunku 5. Za graniczną wartość twardości, dla stali $S 460 \mathrm{~N}$ przyjęto 380 HV10 zgodnie z normą PN-EN ISO 15614-1:2008.

We wszystkich złączach wykonanych w środowisku wodnym, jak i powietrznym stwierdzono przekroczenie granicznej wartość twardości 380 HV10. Przykładowe wyniki pomiarów twardości zaprezentowano na rysunku 6 . W tablicy $V$ zaprezentowano zestawienie maksymalnych twardości SWC poszczególnych złączy.

a)

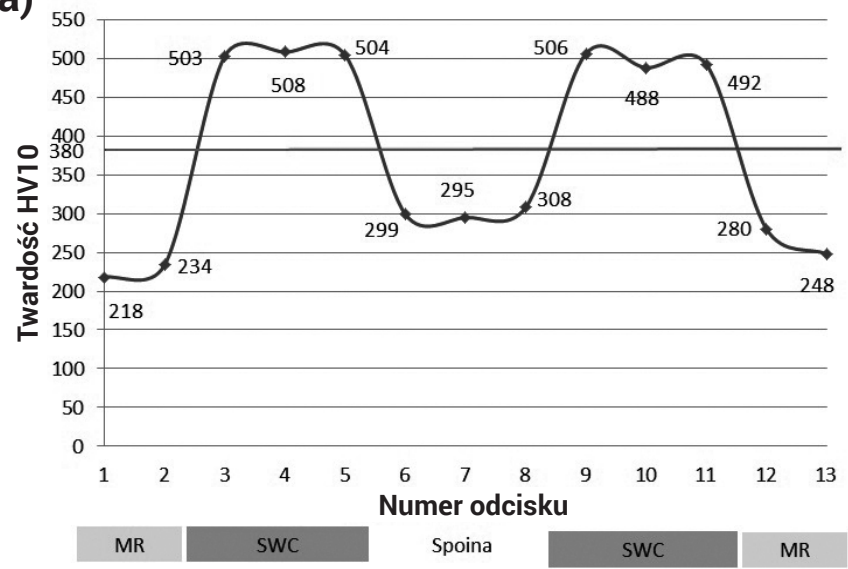

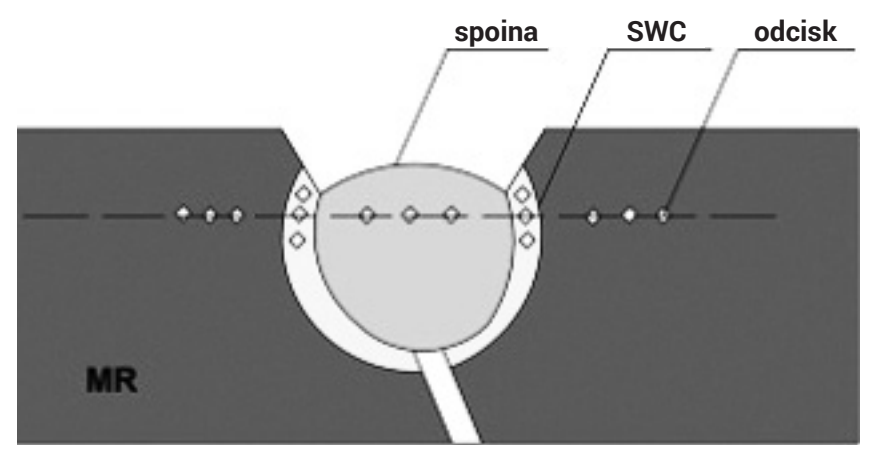

Rys. 5. Schemat rozmieszczenia odcisków podczas badań twardości - próba CTS

Fig. 5. Schematic layout of hardness testing - CTS test

b)

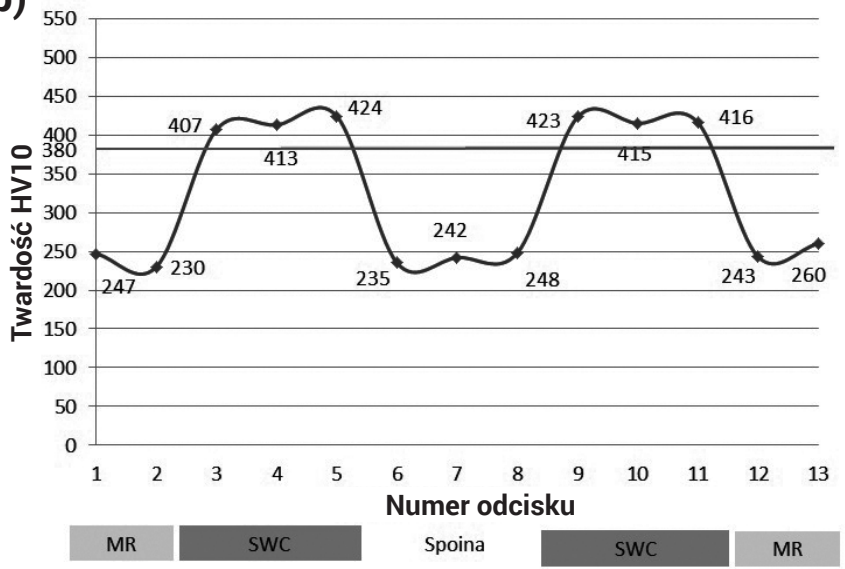

Rys. 6. Rozkład pomiarów twardości dla stali S460N: a) rozkład twardości złącza próbki W3 spawanej pod wodą, HV10max=508; b) rozkład twardości złącza próbki P11 spawanej na powietrzu, HV10max=424

Fig. 6. Layout results of hardness tests for S460N steel. Schematic layout of hardness testing: a) hardness distribution across W3 joint welded under the water, HV10max=506; b) hardness distribution across P11 joint welded in the air, HV10max=424

Tablica V. Wyniki pomiarów twardości

Table V. Results of hardness tests

\begin{tabular}{|c|c|c|c|c|c|c|c|c|c|c|c|c|}
\hline \multirow[b]{2}{*}{ Nr próbki } & \multicolumn{10}{|c|}{ Próbki spawane pod wodą } & \multicolumn{2}{|c|}{$\begin{array}{c}\text { Próbki spawane } \\
\text { na powietrzu }\end{array}$} \\
\hline & W1 & W2 & W3 & W4 & W5 & W6 & W7 & W8 & W9 & W10 & $\mathrm{P} 11$ & P12 \\
\hline $\begin{array}{l}\text { Maksymalna } \\
\text { twardość HV10 }\end{array}$ & 494 & 506 & 508 & 499 & 499 & $x$ & 464 & $x$ & 491 & 498 & 424 & 420 \\
\hline
\end{tabular}

\section{Podsumowanie i wnioski}

W wyniku przeprowadzonych badań próbą Tekken stali S460N stwierdzono, że charakteryzuje się ona złą spawalnością w warunkach spawania mokrego elektrodami otulonymi. Złącza zawierały liczne pęknięcia, które w większości przypadków przebiegały przez całą grubość spoin, dzieląc próbkę na dwie części. Wyniki pomiarów twardości metodą Vickersa (HV10) pokazały, iż we wszystkich wykonanych próbkach nastąpiło przekroczenie przyjętej zgodnie z normą PN-EN ISO 156141:2008 wartości 380 HV10. Sposobem obniżenia twardości złączy może być zastosowanie techniki ściegu odpuszczającego $[21,22]$. W przypadku wykonywania złączy na powietrzu stal ta wymaga podgrzewania wstępnego. W wyniku przeprowadzonych badań sformułowano wnioski:

1. Stal S460N charakteryzuje się wysoką skłonnością do powstawania pęknięć zimnych w warunkach spawania mokrego elektrodami otulonymi, natomiast podczas spawania na powietrzu jej spawalności jest ograniczona.

2. Zarówno w próbkach spawanych pod wodą, jak i na powietrzu wykazano obecność pęknięć zimnych, które są charakterystyczne dla spawanego materiału oraz spawania w środowisku wodnym.

3. Twardość wszystkich wykonanych złączy przekroczyła maksymalną twardość zgodnie z zastosowanym kryterium akceptacji (380 HV10) zgodnie z normą PN-EN ISO 15614-1:2008. Aby obniżyć wysoką twardość złączy wykonanych pod wodą (powyżej 500 HV10) należy zastosować technikę ściegu odpuszczającego. 


\section{Literatura}

[1] Fydrych D., Rogalski G., Łabanowski J.: Problems of underwater welding of higher-strength low alloy steels, Institute of Welding Bulletin, vol. 58, iss. 5, 2014, pp. 185-190.

[2] Rogalski G., Łabanowski J., Fydrych D., Tomków J.: Bead-on-plate weIding of S235JR steel by underwater local dry chambet proces, Polish Maritime Research, 21, 2014, pp. 58-64.

[3] Hu Y., Shi Y.H., Shen X.Q., Wang Z.M.: Microstructore, pitting corrosion resistance and impact toughness of duplex stainless steel underwater dry hyperbaric flux-cored arc, Materials, 10 (12), 2008, pp. 1443.

[4] Gao W.B., Wang D.P., Cheng F.J., Deng C.Y., Xu W.: Underwater wet weIding for HSLA steels: chemical composition, defects, microstructures, and mechanical properties, Acta Metallurgica Sinica (English Letters), 9, 2015, pp. 1097-1108.

[5] Gao W., Wang D., Cheng F., Deng C., Liu Y., Xu W.: Enhancement of the fatigue strength of underwater wet welds by grinding and ultrasonic impact treatment, Journal of Materials Processing Technology, 223, 2015, pp. 305-312.

[6] Fydrych D., Łabanowski J., Tomków J., Rogalski G.: Cold cracking of underwater wet welded S355G10+N high strength steel, Advances in Materials Science, vol. 16, 2015, pp. 48-56.

[7] Rogalski G., Fydrych D., Łabanowski J.: Ocena możliwości naprawy rurociągu podwodnego ze stali API 5L X65 przy zastosowaniu spawania mokrego, Przegląd Spawalnictwa, nr 5, 2015, s. 83-90.

[8] Sun Q.J., Cheng W.Q., Liu Y.B., Wang J.F., Cai C.W., Feng J.C.: Microstructure and mechanical properities of ultrasonic assisted underwater wet welding joints, Materials \& Design, 103, 2016, pp. 63-70.

[9] Fydrych D., Rogalski G., Tomków J., Łabanowski J.: Skłonność do tworzenia pęknięć zimnych złączy ze stali S420G2+M spawanej pod wodą metodą mokrą, Przegląd Spawalnictwa, nr 10, 2013, s. 65-71.

[10] Padilla E., Chawla N., Silva L.F., dos Santos V.R., Paciornik S.: Image analysis of cracks in the weld metal of a wet welded steel joint by three dimensional (3D) X-ray microtomography, Materials Characterization, 83, 2013, pp. 139-144.

[11] Kurji R., Coniglio N.: Towards the establishment of weldability test standards for hydrogen-assisted cold cracking, The International Journal of Advanced Manufacturing Technology, 77, 2015, pp. 1581-1597.
[12] Świerczyńska A., Fydrych D., Rogalski G.: Diffusible hydrogen management in underwater wet self-shielded flux cored arc welding, International Journal of Hydrogen Energy, vol 42, iss 38, 2017, pp. 24532-24540.

[13] Guo N., Yang Z., Wang M., Yuan X., Feng J.: Microstructure and mechanical properties of an underwater wet welded dissimilar ferritic/austenitic steel joint. Strength of Materials, 47, 1, 2015, pp. 12-18.

[14] Fydrych D., Łabanowski J., Rogalski G., Haras J., Tomków J., Świerczyńska A., Jakóbczak P., Kostro Ł.: Weldability of S500MC steel in underwater conditions. Advances in Materials Science, vol. 14, iss. 2, 2014, pp. 37-45.

[15] Omajene J.E., Martikainen J., Wu H., Kah P.: Optimization of underwater wet welding process parameters using neural network, International Journal of Mechanical and Materials Engineering, 1, 2014, pp. 9-26.

[16] Łabanowski J., Prokop-Strzelczyńska K., Rogalski G., Fydrych D.: The effect of wet underwater welding on cold cracking susceptibility of duplex stainless steel, Advances in Materials Science, vol. 16., iss. 2, 2016, pp. 68-77.

[17] Garašić I., Krajl S., Kožuh S.: Investigation into cold cracking in underwater wet welding of API5L X70 steel, Transactions of FAMENA, 3, 2009, pp. 25-34.

[18] Pańcikiewicz K., Zielińska-Lipiec A., Tuz L., Rakoczy Ł.: Ocena skłonności do pęknięć zimnych złączy spawanych stali w próbie implantacyjnej, Przegląd Spawalnictwa, nr 4, 2016, s. 63-65.

[19] Kannengiesser T., Boellinghaus T.: Cold cracking tests-an overview of present technologies and applications, Welding in the World, 1, 2013, pp. 3-37.

[20] Zhang H.T., Dai X.Y., Feng J.C., Hu L.L.: Preliminary investigation on realtime induction heating-assisted underwater wet welding, Welding Journal, 1, 2015, pp. 8-15.

[21] Fydrych D., Tomków J., Rogalski G., Łabanowski J.: Wpływ techniki ściegu odpuszczającego na spawalność stali $\mathrm{S} 355 \mathrm{G} 10+\mathrm{N}$ pod wodą, Przegląd Spawalnictwa, nr 9, 2015, s. 29-33.

[22] Fydrych D., Świerczyńska A., Rogalski G., Łabanowski J.: Temper bead welding of S420G2+M steel in water environment, Advances in Materials Science, vol. 16, iss. 4, 2016, pp. 5-16. 